Article

\title{
Origin of Structural Change Driven by A-Site Lanthanide Doping in $\mathrm{ABO}_{3}$-Type Perovskite Ferroelectrics
}

\author{
Lan Xu ${ }^{1,2}$, Zujian Wang ${ }^{1,2}$, Bin Su ${ }^{1,3}$, Chenxi Wang ${ }^{1}$, Xiaoming Yang ${ }^{1}$, Rongbing Su ${ }^{1}$, \\ Xifa Long ${ }^{1,2,3}$ and Chao $\mathrm{He}^{1,2,3, *(\mathbb{D})}$ \\ 1 Key Laboratory of Optoelectronic Materials Chemistry and Physics, Fujian Institute of Research on the \\ Structure of Matter, Chinese Academy of Sciences, Fuzhou 350002, China; xulan@fjirsm.ac.cn (L.X.); \\ wangzujian@fjirsm.ac.cn (Z.W.); subin@fjirsm.ac.cn (B.S.); cxwong123@outlook.com (C.W.); \\ xmyang@fjirsm.ac.cn (X.Y.); surongbing@fjirsm.ac.cn (R.S.); lxf@fjirsm.ac.cn (X.L.) \\ 2 Fujian Science \& Technology Innovation Laboratory for Optoelectronic Information of China, \\ Fuzhou 350108, China \\ 3 Fujian College, University of Chinese Academy of Sciences, Fuzhou 350002, China \\ * Correspondence: hechao@fjirsm.ac.cn
}

Received: 28 April 2020; Accepted: 26 May 2020; Published: 29 May 2020

\begin{abstract}
Lanthanide doping is widely employed to tune structural change temperature and electrical properties in $\mathrm{ABO}_{3}$-type perovskite ferroelectric materials. However, the reason that A-site lanthanide doping leads to the decrease of the Curie temperature is still not clear. Based on the reported Curie temperature of lanthanides ( $\mathrm{Ln}$ ) doped in two classic ferroelectrics $\mathrm{PbTiO}_{3}$ and $\mathrm{BaTiO}_{3}$ with $\mathrm{A}^{2+} \mathrm{B}^{4+} \mathrm{O}_{3}$-type perovskite structure, we discussed the relationship between the decrease rate of Curie temperature $\left(\Delta T_{C}\right)$ and the bond strength variance of A-site cation $(\sigma)$. For $\mathrm{Nd}$ ion doped $\mathrm{Pb}\left(\mathrm{Mg}_{1 / 3} \mathrm{Nb}_{2 / 3}\right) \mathrm{O}_{3}-\mathrm{PbTiO}_{3}(\mathrm{Nd}-\mathrm{PMNT})$ ferroelectric crystal as an example, the internal factors of the dramatic decline of the Curie temperature induced by A-site $\mathrm{Nd}$ doping were investigated under a systematic study. The strong covalent bonds of Ln-O play an important role in A-site Ln composition-induced structural change from ferroelectric to paraelectric phase, and it is responsible for the significant decrease in the Curie temperature. It is proposed that the cells become cubic around the Ln ions due to the strong covalent energy of Ln-O bonding in A-site Ln doped $\mathrm{A}^{2+} \mathrm{B}^{4+} \mathrm{O}_{3}$ perovskite ferroelectrics.
\end{abstract}

Keywords: structural change; lanthanides; ferroelectric materials

\section{Introduction}

$\mathrm{ABO}_{3}$-type ferroelectric perovskite materials, where $\mathrm{A}$ is $\mathrm{Pb}^{2+}, \mathrm{Ba}^{2+}$, etc. and $\mathrm{B}$ is $\mathrm{Ti}^{4+}, \mathrm{Zr}^{4+}, \mathrm{In}^{3+}$, $\mathrm{Mg}^{2+}, \mathrm{Zn}^{2+}, \mathrm{Nb}^{5+}, \mathrm{Ta}^{5+}$, etc., have been extensively studied for their structures, dielectric, ferroelectric, piezoelectric and related properties [1-4]. It has been repeatedly reported that the properties of perovskite ferroelectrics can be varied by doping or substituting ions (or ions group) on A-/B-sites. For instance, ferroelectric properties are likely to be changed by varying compositions and elements on B-site, such as $\mathrm{Pb}(\mathrm{In}, \mathrm{Mg}, \mathrm{Nb}, \mathrm{Ti}) \mathrm{O}_{3}[5,6], \mathrm{Pb}\left(\mathrm{Sc}, \mathrm{Mg}, \mathrm{Nb}, \mathrm{Ti}_{3} \mathrm{O}_{3}\right.$ [7], $\mathrm{Pb}(\mathrm{Y}, \mathrm{Mg}, \mathrm{Nb}, \mathrm{Ti}) \mathrm{O}_{3}[8]$. For A-site substitution, it is possible to change the transition temperature, i.e., $\mathrm{PbTiO}_{3}[9], \mathrm{BaTiO}_{3}$ [10]. Different from the detailed study of the B-site substitution in perovskite ferroelectrics, the research on the mechanism of A-site ion doping is still insufficient.

It is well known that the A-site cation has 12-fold coordination and the B-site cation is surrounded by an octahedron of oxygen anions in 6-fold coordination in $\mathrm{ABO}_{3}$-type perovskite. Many perovskite materials undergo a phase transition from cubic symmetry to lower symmetry ones with distorted 
cubic form as temperature decreases. Based on the geometrical packing, Goldschmidt [11] proposed the tolerance factor $t$ for perovskites, defined as:

$$
t=\frac{r_{A}+r_{O}}{\sqrt{2}\left(r_{B}+r_{O}\right)}
$$

where $r_{A}, r_{B}$ and $r_{O}$ are ionic radii of atoms $\mathrm{A}, \mathrm{B}$ and $\mathrm{O}$, respectively. The tolerance factor could be used to assess the distortions in a perovskite material. In an ideal cubic perovskite, the tolerance factor equals 1. A stable perovskite structure usually lies in the tolerance factor range from 0.88 to 1.09 , summarized from the known perovskites $[12,13]$. The ionic radius is an important factor either in holding a stable perovskite structure or ion doping. In terms of tuning performance, lanthanide ion doping is an effective method. Lanthanide atoms possess the special electron orbital configuration in the general $[\mathrm{Xe}] 4 f{ }^{\mathrm{n}} 5 d^{\mathrm{m}}{ }^{2} \mathrm{~s}^{2}(\mathrm{n}=0-14, \mathrm{~m}=0,1)$. For lanthanides, the energy of $5 d$ and $4 f$ orbital is very close and the $5 d$ orbital only has one or zero electron. The lanthanide ions have the lanthanide contraction phenomena in the atomic radius and ionic radius. Most researches on lanthanide ion doping or substitution for $\mathrm{ABO}_{3}$-type perovskite ferroelectrics have focused on the Curie temperature, electrical properties and generating new features (e.g., photoluminescence). However, there are few works on the systematic study of the internal mechanism, such as exploring intrinsic structural nature and the physical origin of the large variation of Curie temperature and other physical properties induced by A-site lanthanide ion doping in perovskite ferroelectrics.

As one of typical $\mathrm{ABO}_{3}$-type perovskite ferroelectrics, $\mathrm{Pb}\left(\mathrm{Mg}_{1 / 3} \mathrm{Nb}_{2 / 3}\right) \mathrm{O}_{3}-\mathrm{PbTiO}_{3}$ (PMNT) [14] perovskite ferroelectrics with ultrahigh piezoelectric coefficients $\left(d_{33}>2000 \mathrm{pC} / \mathrm{N}\right)$ and electromechanical coupling factors $\left(k_{33}>90 \%\right)$ are considerably promising candidates for applications in transducers and actuators. For B-site lanthanide doping, $\mathrm{Pb}\left(\mathrm{Ho}_{1 / 2} \mathrm{Nb}_{1 / 2}\right) \mathrm{O}_{3}-\mathrm{Pb}\left(\mathrm{Mg}_{1 / 3} \mathrm{Nb}_{2 / 3}\right) \mathrm{O}_{3}-\mathrm{PbTiO}_{3}$ [15], $\mathrm{Pb}\left(\mathrm{Yb}_{1 / 2} \mathrm{Nb}_{1 / 2}\right) \mathrm{O}_{3}-\mathrm{Pb}\left(\mathrm{Mg}_{1 / 3} \mathrm{Nb}_{2 / 3}\right) \mathrm{O}_{3}-\mathrm{PbTiO}_{3}$ [16], $\mathrm{Pb}\left(\mathrm{Lu}_{1 / 2} \mathrm{Nb}_{1 / 2}\right) \mathrm{O}_{3}-\mathrm{Pb}\left(\mathrm{Mg}_{1 / 3} \mathrm{Nb}_{2 / 3}\right) \mathrm{O}_{3}-\mathrm{PbTiO}_{3}$ [17] and Er-doped PMNT [18] have been studied. As reported for A-site lanthanide doping in PMNT, $2.5 \mathrm{~mol} \% \mathrm{Sm}$-doped PMNT ceramics [19] have a lower Curie temperature of $89^{\circ} \mathrm{C}$ compared with undoped PMNT. With increasing $\mathrm{La}^{3+}$ contents from $2.5 \mathrm{~mol} \%$ to $6.5 \mathrm{~mol} \%$, the Curie temperature of La-doped PMNT ceramics decreases dramatically from $51{ }^{\circ} \mathrm{C}$ to $-41^{\circ} \mathrm{C}$ [20]. A-site lanthanide doping could significantly affect the change of the Curie temperature in the ferroelectric materials. To explore its underlying causes, $\mathrm{Nd}$ element whose atom number is in the medium of $\mathrm{La}$ and $\mathrm{Sm}$ was employed to be doped in PMNT single crystals in this work. The effect of $\mathrm{Nd}^{3+}$ ions on the structural change and electrical properties of Nd-doped PMNT (Nd-PMNT) single crystals were investigated and the physical origin of the structural change induced by A-site lanthanide doping were discussed.

\section{Materials and Methods}

A series of $\left(\mathrm{Nd}_{x} \mathrm{~Pb}_{1-3 x / 2}\right)\left[\left(\mathrm{Mg}_{1 / 3} \mathrm{Nb}_{2 / 3}\right)_{1-y} \mathrm{Ti}_{y}\right] \mathrm{O}_{3}$ (abbreviated as $x$ Nd-PMNT100y hereafter) single crystals were grown using top-seeded solution-growth method. The crystals with actual compositions of 2.19\%Nd-PMNT31, 2.03\%Nd-PMNT39, 0.58\%Nd-PMNT38, 5.55\%Nd-PMNT37 and 15\%Nd-PMNT37 were obtained and their chemical compositions were checked by using inductively coupled plasma optical emission spectroscopy (ICP-OES, Ultima 2, Horiba Jobin Yvon Inc., Longjumeau Cedex, France). The X-ray powder diffraction (XRD) data of samples were performed on a Rigaku diffractometer (Rigaku MiniFlex600, Rigaku, Tokyo, Japan). Single crystals of [001]-oriented plates were polished and their both sides were covered with silver electrodes for the electrical properties measurements. Dielectric measurements above room temperature were performed on an impedance analyzer (Novocontrol GmbH, Montabaur, Germany) Dielectric properties were measured using another impedance analyzer below room temperature (E4990A, Agilent Technologies, Santa Clara, CA, USA). The polarization-electric field $(P-E)$ hysteresis loops and current-electric field $(I-E)$ were measured by a ferroelectric analyzer (aix-ACCT TF2000, Aachen, Germany). A quasi-static d33 meter (Model ZJ-4AN, Institute of Acoustics, Chinese Academy of Sciences, Beijing, China) was used to measure the piezoelectric coefficient $d_{33}$. Raman experiments were performed on Raman spectrometer using the 
radiation of $633 \mathrm{~nm}$ as the exciting source (Horiba LabRAM HR 800 Evolution, Tokyo, Japan). The TEM image was obtained by field emission transmission electron microscope (FEI Tecnai F20, Hillsboro, OR, USA). For preparing TEM sample, the powders of single crystal were sonicated in absolute ethanol to diffuse.

\section{Results}

Nd-PMNT crystals with different compositions were studied. Nd-PMNT crystals with low Nd doping concentrations and different $\mathrm{PbTiO}_{3}(\mathrm{PT})$ contents were investigated firstly. The XRD patterns in Figure S1 (supplementary information) show that 2.19\%Nd-PMNT31 and 2.03\%Nd-PMNT39 single crystals had a rhombohedral perovskite phase $(R 3 m)$ and a tetragonal perovskite phase $(P 4 m m)$, respectively. It displays that $\mathrm{Nd}-\mathrm{PMNT}$ crystals with low $\mathrm{Nd}$ doping contents have the structural change from rhombohedral to tetragonal ferroelectric phase with increasing PT contents, as the same as pure PMNT. The ferroelectric hysteresis loops and temperature dependent dielectric constants at different frequencies are shown in Figure 1. For 2.19\%Nd-PMNT31 crystals, a broad dielectric peak shifted from $93{ }^{\circ} \mathrm{C}$ at $1 \mathrm{~Hz}$ to $99{ }^{\circ} \mathrm{C}$ at $10^{5} \mathrm{~Hz}$, indicating the typical relaxor behavior (Figure 1c). The $2.03 \%$ Nd-PMNT39 crystals exhibited normal ferroelectric behavior with sharp dielectric peaks at $142{ }^{\circ} \mathrm{C}$ (Figure 1d). Thus, the variation of crystal structure and dielectric properties of Nd-PMNT systems with low $\mathrm{Nd}$ contents are similar to that of PMNT.

(a)

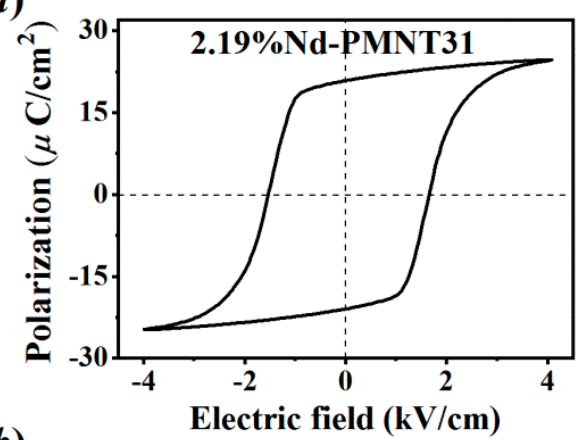

(b)



(c)

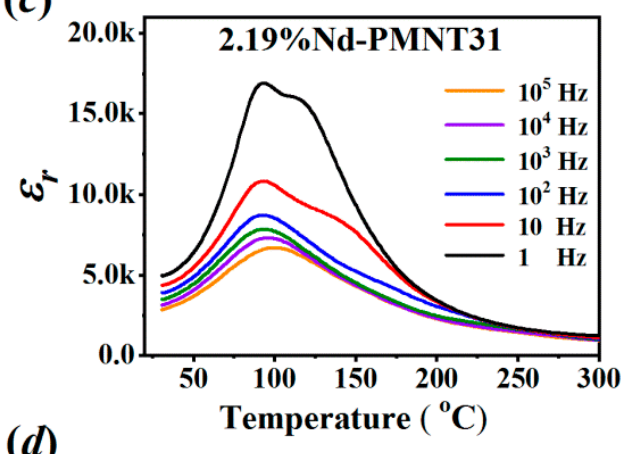

(d)

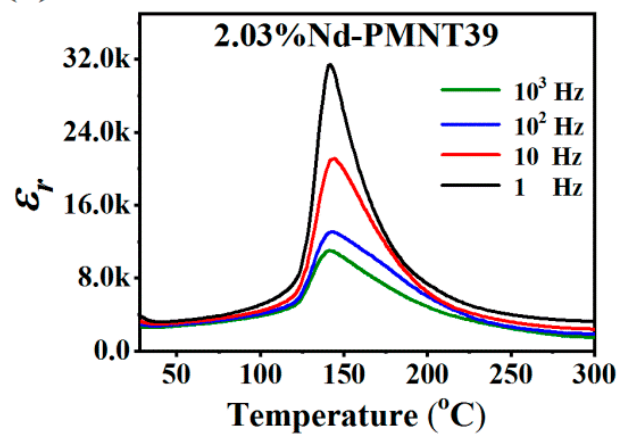

Figure 1. The polarization-electric field $(P-E)$ hysteresis loops and the temperature dependence of dielectric constant $\varepsilon_{\mathrm{r}}$ for (a,c) 2.19\%Nd-PMNT31 and (b,d) 2.03\%Nd-PMNT39 single crystals.

Then, Nd-PMNT crystals with increasing Nd contents were studied. The measured XRD data of $0.58 \%$ Nd-PMNT38, $5.55 \%$ Nd-PMNT37, $15 \%$ Nd-PMNT37 were refined by the Rietveld method with GSAS 2000 [21] as shown in Figure 2. The fitting residuals $R_{\mathrm{wp}}$ and $R_{\mathrm{p}}$ for $0.58 \%$ Nd-PMNT38 were $13 \%$ and $9.2 \%$, for $5.55 \%$ Nd-PMNT37 were $11 \%$ and $9.1 \%$ and for $15 \%$ Nd-PMNT37 were $13 \%$ and $10 \%$, respectively. The lattice parameters, atom coordinates and temperature factor $U_{\text {iso }}$ based on the refinement results were listed in Table S1 and Table S2 in the Supplementary Materials. It is shown that $0.58 \%$ Nd-PMNT38 crystals have only tetragonal perovskite phase with space group P4mm, $5.55 \%$ Nd-PMNT37 crystals consist of tetragonal perovskite phase $(P 4 \mathrm{~mm})$ with $71 \mathrm{wt} \%$ and cubic perovskite phase $(\operatorname{Pm} \overline{3} m)$ with $29 \mathrm{wt} \%$, and $15 \%$ Nd-PMNT37 crystals exhibit pure cubic perovskite 
phase with space group $P m \overline{3} m$. In crystal structure, Nd-PMNT crystals underwent a successive structural change from a tetragonal phase to a coexisting phase of tetragonal and cubic phase then to a cubic phase as $\mathrm{Nd}$ contents increase. Figure $\mathrm{S} 2$ shows the clear change of structure after $\mathrm{Nd}^{3+}$ doping.
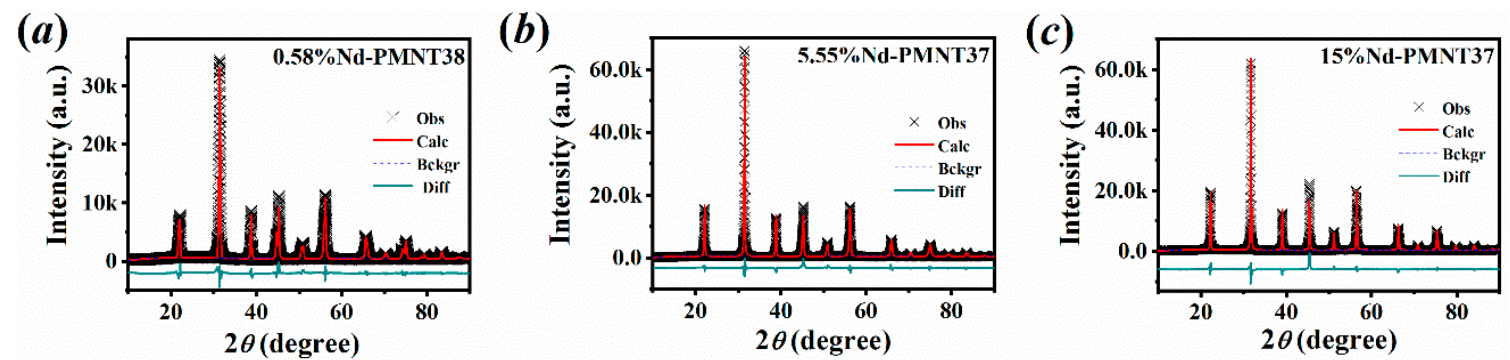

Figure 2. (a-c) XRD patterns of Nd-PMNT crystalline powders were refined by the Rietveld method. Experimental, fitted, differences curves are shown by crosses, red solid and green solid curves, respectively.

The ferroelectric hysteresis loops ( $P$-E loops), current-electric field $(I-E)$ curves and the temperature dependence of dielectric constant also confirmed this. Figure 3 a displays that $0.58 \%$ Nd-PMNT38 crystals exhibit well-development saturated $P-E$ loops and two main current peaks corresponding to polarization switching at coercive field $\left(E_{\mathrm{C}}\right)$, showing the typical ferroelectric properties. With increasing Nd doping contents, $5.55 \%$ Nd-PMNT37 crystals exhibit clamped $P$-E hysteresis loops accompanied by four apparent current peaks (Figure $3 \mathrm{~b}$ ). Further raising Nd contents, the $P$ - $E$ loops are displayed as linear feature and there is no current peak in $I-E$ curves, indicating the paraelectric phase for $15 \%$ Nd-PMNT37 crystals (Figure $3 c$ ). It is clearly seen that the coercive field $E_{C}$ and the remanent polarization $P_{\mathrm{r}}$ decrease and the ferroelectricity finally vanishes as $\mathrm{Nd}$ contents increase. In addition, The Curie temperatures of $0.58 \%$ Nd-PMNT38, 5.55\%Nd-PMNT37 and 15\%Nd-PMNT37 crystals were $142{ }^{\circ} \mathrm{C}, 35^{\circ} \mathrm{C}$ and $-3{ }^{\circ} \mathrm{C}$ in the temperature dependent dielectric constant curves (Figure $3 \mathrm{~d}-\mathrm{f}$ ), respectively. The Curie temperature of Nd-PMNT crystals gradually decreased as $\mathrm{Nd}$ doping contents increased. It is consistent with the change of structure undergoing a tetragonal-cubic transition.

The above evolution of $P$-E hysteresis loops of Nd-PMNT single crystals with increasing Nd contents showed an agreement of the temperature dependence of ferroelectric properties presented as follows. Figure 4 shows the temperature dependence of ferroelectric and dielectric properties for $2.19 \%$ Nd-PMNT31 crystals. It can be easily seen that the sample shows the typical ferroelectric $P$ - $E$ loops below $70{ }^{\circ} \mathrm{C}$ (Figure $4 \mathrm{~b}-\mathrm{d}$ ). Around the Curie temperature $T_{\mathrm{C}}$ of $93^{\circ} \mathrm{C}$, the hysteresis loops show the constricted loops, and four switching peaks are shown in I-E curves (Figure 4e), similarly to the loops of $5.55 \%$ Nd-PMNT37 crystals (Figure $3 \mathrm{~b}$ ). The $P$-E loops are getting thinner and thinner until they become straight lines just like the loops of 15\%Nd-PMNT37 (Figure 3c) when the temperature was higher than $114{ }^{\circ} \mathrm{C}\left(T_{\mathrm{i}}\right)$ as shown in Figure $4 \mathrm{f}-\mathrm{i}$. The temperature dependence of dielectric constant (Figure 4a) shows another hump at $T_{\mathrm{i}}$ besides the peak at $T_{\mathrm{C}}$, indicating that there may exist a structural change in the interval of $T_{\mathrm{C}}$ and $T_{\mathrm{i}}$. Thence, the temperature-induced phase transition in $2.19 \% \mathrm{Nd}-\mathrm{PMNT} 31$ and Nd composition-driven structural change in Nd-PMNT crystals show the same transitions from ferroelectric to paraelectric phase after $\mathrm{Nd}$ doping. 
(a)

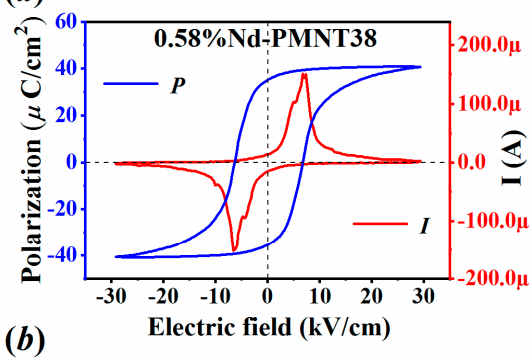

(b)

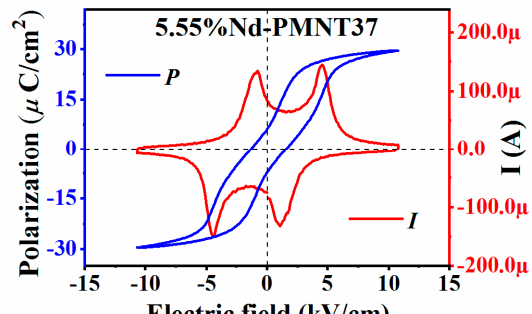

(c)

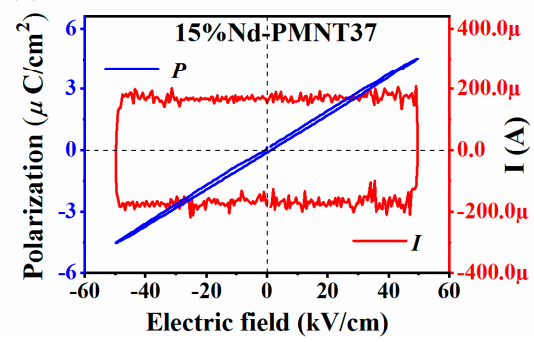

(d)

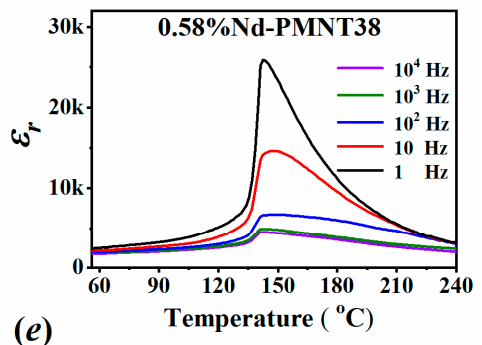

(e)



(f)

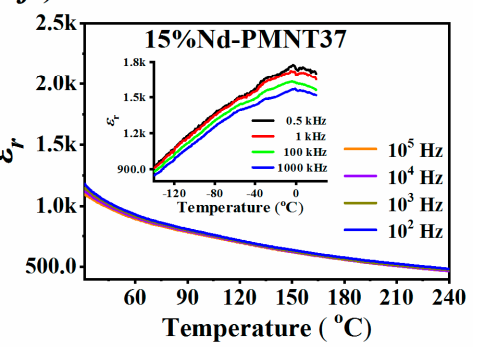

Figure 3. The polarization-electric field $(P-E)$ hysteresis loops and the current-electric field (I-E) curves of (a) $0.58 \%$ Nd-PMNT38, (b) 5.55\%Nd-PMNT37 and (c) 15\%Nd-PMNT37 single crystals at room temperature $(2 \mathrm{~Hz})$. The temperature dependence of dielectric constant $\varepsilon_{r}$ for (d) $0.58 \% \mathrm{Nd}-\mathrm{PMNT} 38$, (e) $5.55 \% \mathrm{Nd}-\mathrm{PMNT} 37$ and (f) $15 \% \mathrm{Nd}-\mathrm{PMNT} 37$ single crystals.

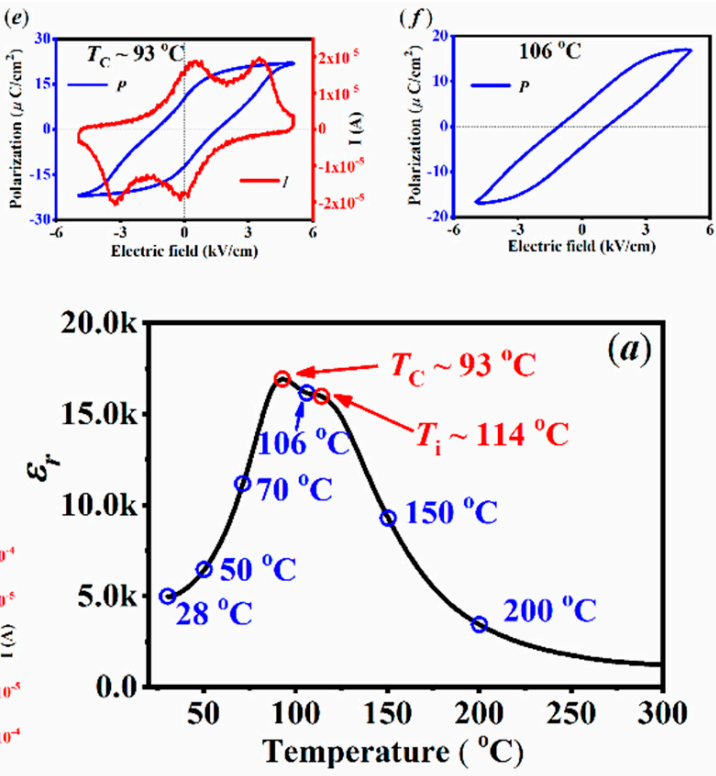


Figure 4. (a) The temperature dependence of dielectric constant $\varepsilon_{r}$ for $2.19 \%$ Nd-PMNT31 single crystals $(1 \mathrm{~Hz}) ;(\mathbf{b}-\mathbf{i})$ the $P$-E hysteresis loops and $I-E$ curves of $2.19 \%$ Nd-PMNT31 single crystals at different temperature. 


\section{Discussion}

The structural change temperature and electrical characteristics of Nd-PMNT crystals induced by $\mathrm{Nd}$ ion doping were confirmed by the macroscopic ferroelectric performance ( $P-E$ loops) and the statistical average structure information (XRD patterns). However, there is little strong and systematic explanation for the dramatic decrease in Curie temperature induced by A-site lanthanide doping in $\mathrm{A}^{2+} \mathrm{B}^{4+} \mathrm{O}_{3}$-type perovskite ferroelectrics. For clear and easy analysis, the influence of the lanthanide doping in two classic ferroelectrics $\mathrm{PbTiO}_{3}$ and $\mathrm{BaTiO}_{3}$ with $\mathrm{A}^{2+} \mathrm{B}^{4+} \mathrm{O}_{3}$-type non-complex perovskite structure was analyzed and discussed. For a stable perovskite structure, the appropriate ionic radii normally should be taken into accounts for the probability of achieving doping or substituting. Since the ions show different ionic radii depending on the lattice position, Table S3 lists the ionic radii of lanthanide ions and commonly used ions in ferroelectrics for the six- and twelve-coordinated (for B- and A-site, respectively) [22]. It can be observed that the ionic radius of the trivalent lanthanide ions decreases from $\mathrm{La}$ to $\mathrm{Lu}$ at the same coordination. In view of the different mechanisms of the effects of A-site and B-site doping on performance, the doping positions of the reported various lanthanide ions-doped $\mathrm{PbTiO}_{3}$ and $\mathrm{BaTiO}_{3}$ were summarized in Table S4 [23-52]. Related to the proximity of the ionic radius of $\mathrm{Pb}^{2+}$ and $\mathrm{Ba}^{2+}$ at 12 -coordination $\left(\mathrm{Pb}^{2+}: 1.49 \AA, \mathrm{Ba}^{2+}: 1.61 \AA\right)$, lanthanides doped exclusively in A-site are La, $\mathrm{Pr}, \mathrm{Nd}, \mathrm{Sm}$ [23-32]. Ce can be doped in the A-site in the form of positive trivalent ions, and it can also be doped in the B-site in the form of positive tetravalent ions [33,34]. Compared with doped $\mathrm{PbTiO}_{3}$, the doped $\mathrm{BaTiO}_{3}$ has been more extensively studied. $\mathrm{Eu}, \mathrm{Gd}, \mathrm{Tb}, \mathrm{Dy}$, $\mathrm{Ho}$, Er are amphoteric and they can occupy either the A-site or B-site in $\mathrm{BaTiO}_{3}$, partially depending on the $\mathrm{Ba} / \mathrm{Ti}$ ratio [35-51]. Gd, Ho and Er with the self-compensation effect can occupy both A and B positions in $\mathrm{BaTiO}_{3}[39,45,46]$.

The significant feature for A-site lanthanide doping in $\mathrm{ABO}_{3}$ ferroelectrics is that Curie temperature sharply decreases as the doping contents increase (e.g., Table S5 [24-27,29,31,53]). Firstly, A-site doping plays an important role in crystal structure and phase transition for $\mathrm{ABO}_{3}$-type perovskite ferroelectrics. Ronald E. Cohen [54] demonstrated that the hybridization of the electron states between B-site cations and oxygen anions was essential for ferroelectricity in most $\mathrm{ABO}_{3}$-type perovskite ferroelectrics, while the A-cation can strongly affect the ground-state perovskite and phase transition, indirectly influencing the $\mathrm{B}-\mathrm{O}$ interaction. Ronald $\mathrm{E}$. Cohen took $\mathrm{PbTiO}_{3}$ and $\mathrm{BaTiO}_{3}$ as example, expounding that even if they have similar cohesive properties (e.g., cell volume $=63.2 \AA^{3}$ and $64.2 \AA^{3}$, respectively), $\mathrm{PbTiO}_{3}$ is tetragonal ground-state perovskite and $\mathrm{BaTiO}_{3}$ is rhombohedral ground-state perovskite. For the case of Ce doping in $\mathrm{BaTiO}_{3}$ [34], the Curie temperature can dramatically decrease from $120^{\circ} \mathrm{C}$ to $40{ }^{\circ} \mathrm{C}$ as the doping of Ce ions increases from $1 \%$ to $4 \%$ at $\mathrm{A}$-site, while the Curie temperature holds constant roughly for Ce doping at B-site. In addition, the effects of amphoteric lanthanide ions (such as Ho, Dy and Er) on the Curie temperature are different at A- and B-site. These all indicate that A-site doping has a huge impact on the phase transition temperature in perovskite ferroelectrics.

When the trivalent lanthanide ions replace some of $\mathrm{A}^{2+}$ ions in $\mathrm{ABO}_{3}$, it would produce charge compensation under the principle of electrical neutrality. The generated vacancies could be at $\mathrm{A}$ site or B site with the corresponding chemical formula $\left(A_{1-3 x / 2}^{2+} L n_{x}^{3+} V_{x / 2}^{0}\right) B^{4+} O_{3}$ or $\left(A_{1-x}^{2+} L n_{x}^{3+}\right)\left(B_{1-x / 4}^{4+} V_{x / 4}^{0}\right) O_{3}$ with the lanthanides $\mathrm{Ln}$ and vacancy site $\mathrm{V}$. The contents of vacancy sites are determined by the contents of trivalent lanthanide ions doped A-site. As La doped $\mathrm{PbTiO}_{3}$ mentioned in [24], the contents of $\mathrm{La}$ substituted $\mathrm{Pb}$ are as high as $30 \mathrm{~mol} \%$, so the generated A-site vacancy would reach $15 \mathrm{~mol} \%$ and the generated B-site vacancy would be $7.5 \mathrm{~mol} \%$. Either way, it is doubtful that the sample still keeps a stable $\mathrm{ABO}_{3}$-type perovskite structure under such high contents of vacancy site. Therefore, the additional factors should be further considered. It is worth noting that lanthanides-O bonding is formed by $s-p-d-f$ nonequivalent hybridization, and its covalent bond energy should theoretically be higher than that of $\mathrm{Pb}-\mathrm{O} / \mathrm{Ba}-\mathrm{O}$ bonding formed by s- $p$ hybridization [55]. The strong covalent bonds of Ln-O may be a key point to enhance structural stability. 
In order to explore the relationship between the Curie temperature reduction and the bond strengths in A-site Ln doping $\mathrm{ABO}_{3}$ perovskite. The mismatch of A-site bond strengths is defined as:

$$
\sigma=\sqrt{E_{\mathrm{Ln}-\mathrm{O}^{2}}-E_{\mathrm{A}-\mathrm{O}^{2}}}
$$

where $E_{\mathrm{Ln}-\mathrm{O}}$ is the bond strengths of $\mathrm{Ln}-\mathrm{O}$, and $E_{\mathrm{A}-\mathrm{O}}$ is the bond strengths of $\mathrm{A}-\mathrm{O}$ (here, $\mathrm{Ln}=\mathrm{La}, \mathrm{Pr}$, $\mathrm{Nd}, \mathrm{Sm} ; \mathrm{A}=\mathrm{Pb}, \mathrm{Ba})$ as shown in Table S3 [56]. Figure 5 shows the decrease rate of $T_{\mathrm{C}}\left(\Delta T_{\mathrm{C}}\right)$ with the bond strengths variance of A-site cation $(\sigma)$, showing a linear increase relationship. The exception one is $\mathrm{Pr}-\mathrm{PbTiO}_{3}$, which can be attributed to the fact that a small fraction of the $\mathrm{Pr}^{4+}$ substituted the $\mathrm{Ti}^{4+}$ site reduces the decrease in the Curie temperature.



Figure 5. The decrease rate of $T_{C}\left(\Delta T_{C}\right)$ with the bond strengths variance of A-site cation $(\sigma)$ based on the Tables S3 and S5.

It means that strong covalent bonds play an important role in the structural change from ferroelectric to paraelectric phase induced by A-site Ln doping in $\mathrm{ABO}_{3}$ perovskite. For Nd-PMNT crystals as example, when doping a trace amount of Ln contents, the materials hold tetragonal ferroelectrics with tetragonal cells $(0.58 \% \mathrm{Nd}-\mathrm{PMNT} 38)$. With increasing Ln contents, the tetragonal materials transform to the materials with a coexistence phase of tetragonal and cubic cells (5.55\%Nd-PMNT37). We propose that the cells become cubic around the Ln ions because of the strong covalent energy of Ln-O bonding. Meanwhile, the cubic cell containing $\mathrm{Ln}^{3+}$ ions can also strongly affect nearby cell structure to be close to a cubic structure cell. In here, the boundary of a crystal is ignored and the crystal is considered to be infinitely extended. Considering the influence of strong covalent energy of Ln-O bonding on the configuration of unit cell, it would tend to form tetragonal/cubic region surrounded by cubic/tetragonal boundary (Figure 6a,b). As the TEM image (Figure 6c) of 5.55\%Nd-PMNT37 crystals has shown, it can be observed that one large area encloses a small region. According to the fast Fourier transform (FFT) patterns, the lattice spacing $(d)$ of $0.2825 \mathrm{~nm}$ (in small region) and $0.2768 \mathrm{~nm}$ (in large area) can be indexed to the $\{110\}$ tetragonal facet $(d=0.2838 \mathrm{~nm})$ and the $\{110\}$ cubic facet $(d=0.2764 \mathrm{~nm})$, respectively. In this TEM image, it shows a transition from $\{110\}$ plane of cubic phase to $\{110\}$ plane of tetragonal phase. Due to periodicity of crystal structure, a series of twisted unit cells would be generated, when tetragonal unit cells transform to cubic unit cells. These twisted unit cells (purple sections in Figure 6a,b) form domain walls with polarity. However, some of the switchable polarization is suppressed by the influence of strong covalent energy, which is highly probability to form a constricted hysteresis loop. This kind hysteresis loops can be observed in 5.55\%Nd-PMNT37 crystals, shown in Figure 3b. This mechanism bears a semblance to the domain wall pinning mechanism [57-59]. As Ln contents continue to increase, the increase in Ln-O bonding with strong covalent energy induces to form more cubic cells, and then periodicity of crystal structure drives tetragonal and cubic cells to reach the cells uniformity, forming the materials entirely composed of cubic cells (15\%Nd-PMNT37). In this evolution, the change of structure and cell parameters of Nd-PMNT was supported by the 
refinement results in Table S1. So far, the structural change process from ferroelectric to paraelectric phase has been completed. Overall, the strong covalent energy of Ln-O bonding plays an important role in A-site lanthanide ions composition-induced structural change from ferroelectric to paraelectric phase in $\mathrm{ABO}_{3}$ perovskite, which results in a significant decrease in the Curie temperature.

(a)



(b)
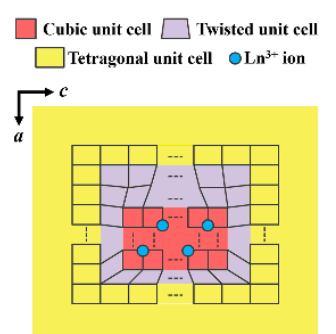

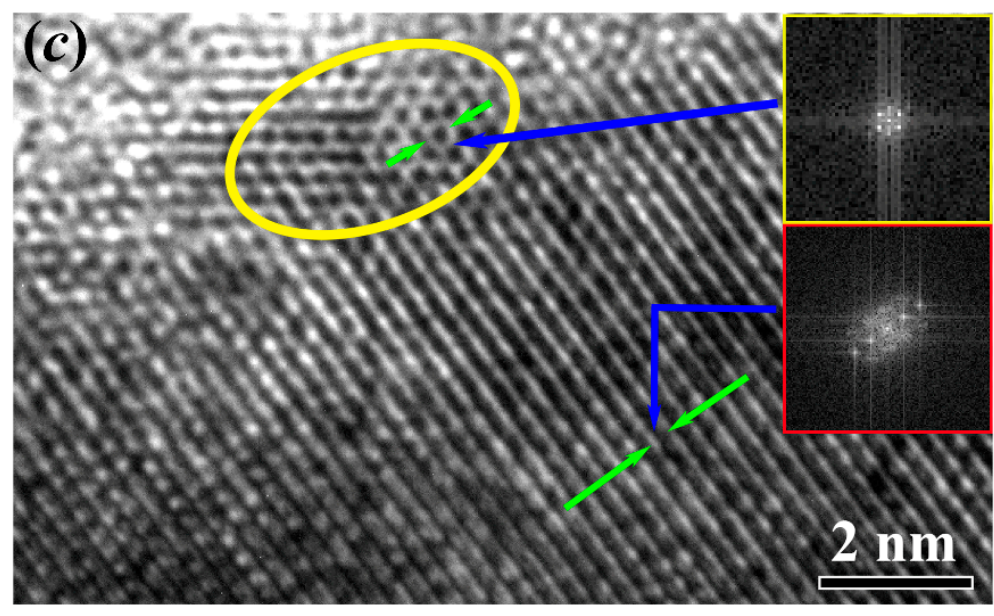

Figure 6. Schematic diagram for two kinds of unit cell arrangements of $\mathrm{Ln}$ doped $\mathrm{ABO}_{3}$ in a region without considering the boundary of a crystal: (a) tetragonal region surrounded by cubic boundary and (b) cubic region surrounded by tetragonal boundary. $\mathrm{Ln}^{3+}$ ions tend to be randomly distributed around the cubic unit cell. (c) The TEM image of 5.55\%Nd-PMNT37 crystals. The upper right corner is the FFT pattern in small region and below is the FFT pattern in large area.

The above microscopic mechanism of Ln composition-induced structural change can reflect in the change of the tetragonal distortion (c/a ratio), that is, the tetragonal distortion gradually decreases to 1 with increasing Ln contents (Table S1), which implies the structural change from tetragonal ferroelectrics to cubic paraelectrics. Then we will explore the mechanism of A-site Ln composition-driven ferroelectric-paraelectric transition in the microscopic scale, by means of Raman analysis. Raman spectra of Nd-PMNT crystals were measured from 100 to $1000 \mathrm{~cm}^{-1}$ (Figure 7), showing roughly similar to those of PMNT [60]. The Raman bands show line-shape broadening due to the disordered occupancy of $\mathrm{Mg}, \mathrm{Nb}$ and $\mathrm{Ti}$ on the $\mathrm{B}$ site and of $\mathrm{Pb}$ and $\mathrm{Nd}$ on the $\mathrm{A}$ site. The Raman peak assignment summarized by A. Welsch et al. [61] shows that the region near peak $F$ and $G$ correspond to $\mathrm{BO}_{6}$ stretching vibration mode and near peak $E$ relates to $\mathrm{BO}_{6}$ bending vibration mode. The difference in the relative intensity of peak $F$ and peak $G$ is the most significant difference between tetragonal 2.03\%Nd-PMNT39 and rhombohedral 2.19\%Nd-PMNT31 crystals, showing that different B-site PT contents directly affect the $\mathrm{BO}_{6}$ stretching vibration mode. In addition, there is the shift of the peak $E$ observed in tetragonal $0.58 \% \mathrm{Nd}$-PMNT38 and $2.03 \% \mathrm{Nd}-\mathrm{PMNT} 39$, showing that the $\mathrm{BO}_{6}$ bending vibration mode could be affected by A-site $\mathrm{Nd}$ doping. It means that the ferroelectricity can be strongly changed by different B-site ions contents, and the ferroelectricity also can be indirectly affected by A-site ions contents. In comparison of the Raman spectra for $0.58 \%$ Nd-PMNT38, 5.55\%Nd-PMNT37 and $15 \%$ Nd-PMNT37, with increasing Nd doping, the whole spectrum tends to weaken and the relative intensities of peaks $F$ and $G$ tend to be the same. The shoulder $C$ assigned to the soft mode $\mathrm{A}_{1}\left(\mathrm{TO}_{1}\right)$ [62] is progressively disappearing as $\mathrm{Nd}$ doping increases, indicating the structural change from ferroelectric to paraelectric phase; that is to say, the A-O stretching mode also at shoulder $C$ [63] gradually weakens and even tends to be silent in $15 \%$ Nd-PMNT37, which depend on the A-site Nd contents. It can be understood that the weakening of the $\mathrm{Nd}-\mathrm{O}$ stretching mode is related to the increase in Nd-O bonding with strong covalent energy. Hence, the gradual increase of strong covalent energy regions is the substantial reason for $\mathrm{Nd}$ composition-driven structural change. In addition, Kaoru Igarashi et al. [64] also concluded that the materials with higher covalent bond energy of A-O 
bond show the lower Curie temperature in perovskite-type titanates. The study of the influence of A-cation disorder on the Curie temperature of $(\mathrm{Ba}, \mathrm{Sr}, \mathrm{Ca}) \mathrm{TiO}_{3}$ ferroelectric perovskites shows that the Curie temperature increases linearly with A-cation size variance [65]. J. P. Attfield demonstrated that the mean A-site cation radius and cation size variance are both important for the transition temperature in $\mathrm{ABO}_{3}$ perovskites of a given transition metal $\mathrm{B}$ [66]. These studies focus on the effect of the changes in the A-site ions radius on the performance. The content ratio of two or three elements in the A-site is important. In this work, the emphasis is on the ability of a certain lanthanide ion to cause the Curie temperature drop on the basis that there are only two elements in A-site. For example, the Curie temperature drop rate of $\mathrm{La}$ doped $\mathrm{PbTiO}_{3}$ can reach $20.87 \mathrm{~K} / \mathrm{at} \%$ (Table S5). Furthermore, the bond strength of A-doped Ln ions gradually decreases from La to Sm, and their ion size also gradually decrease. Therefore, the bond strength variance and ion size variance have the similar effect on the decrease of $T_{C}$, which requires the further study.

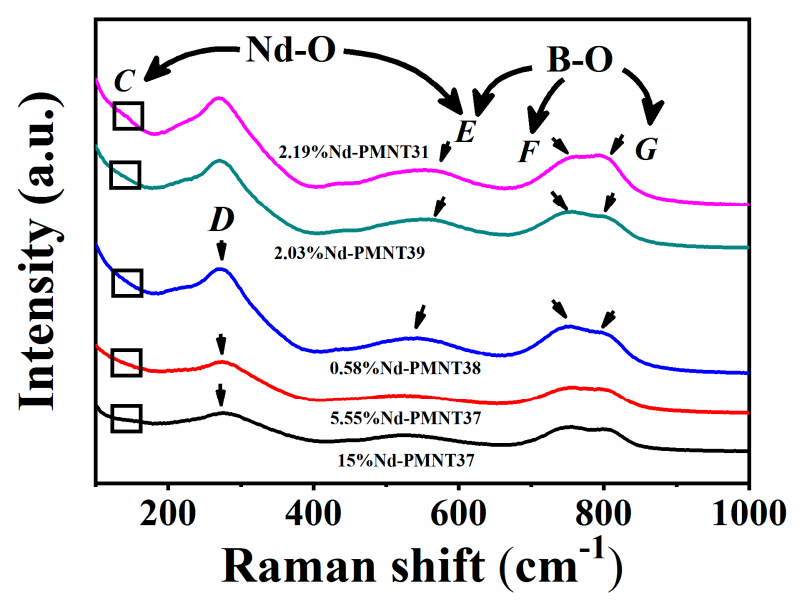

Figure 7. Raman scattering spectra of Nd-PMNT single crystals.

\section{Conclusions}

Based on a lot of literature, the physical mechanism of A-site lanthanide doping in $\mathrm{ABO}_{3}$-type perovskite ferroelectrics was discussed. Based on the previous reported A-site Ln doped in $\mathrm{PbTiO}_{3}$ and $\mathrm{BaTiO}_{3}$, we discussed the relationship between the decrease rate of Curie temperature and the bond strengths variance of A-site cation. As an example of A-site doping, the Curie temperature of Nd-PMNT crystals gradually decreased and the structure underwent the transition from tetragonal to cubic phase as $\mathrm{Nd}$ doping contents increased, which were explored by means of the research of crystal structure, ferroelectric properties, dielectric properties, TEM image and Raman spectra. In this structural change, the strong covalent bonds of Ln-O play an important role in the sharp decline of Curie temperature. It is proposed that the cells become cubic around the Ln ions due to the strong covalent energy of Ln-O bonding. This work presents a Curie temperature prediction method of perovskite ferroelectric materials using the bond strengths of A-site cation. For example, look for ferroelectric materials with high Curie temperature.

Supplementary Materials: The following are available online at http://www.mdpi.com/2073-4352/10/6/434/s1, Figure S1: XRD patterns of $2.19 \%$ Nd-PMNT31 and $2.03 \%$ Nd-PMNT39 crystals, indexed to $P m \overline{3} m$ cubic system. Figure S2: (a) The powder XRD patterns of Nd-PMNT crystals and (b) the enlarged $(200)_{C}$ reflections of the different compositions. Table S1: Lattice parameters, cell volumes and theoretical densities of Nd-PMNT crystals based on the Rietveld refinement. Table S2: Fractional coordinates $(x, y$ and $z)$ and $U_{\text {iso }}$ of all atoms of Nd-PMNT crystals for Rietveld refinement. Table S3: The Shannon ionic radii [22], bond strengths in diatomic molecules at $298 \mathrm{~K}$ [56] of $\mathrm{Pb}^{2+}, \mathrm{Ba}^{2+}, \mathrm{Ti}^{4+}, \mathrm{Mg}^{2+}, \mathrm{Nb}^{5+}$ and lanthanide ions commonly used in perovskite ferroelectric materials. Table S4: The previous reported ions occupancy of lanthanide ions in $\mathrm{PbTiO}_{3}$ and $\mathrm{BaTiO}_{3}$. Table S5: The decrease rate of $T_{C}$ in $\mathrm{PbTiO}_{3}$ and $\mathrm{BaTiO}_{3}$ systems with increasing A-site Ln doping contents $(\geq 5$ at $\%)$. 
Author Contributions: Conceptualization, L.X., C.H. and X.L.; methodology, L.X.; validation, Z.W., X.Y. and R.S.; formal analysis, C.W. and B.S.; investigation, L.X.; writing-original draft preparation, L.X.; writing-review and editing, C.H.; supervision, C.H. and X.L. All authors have read and agreed to the published version of the manuscript.

Funding: This research was funded by the Strategic Priority Research Program of the Chinese Academy of Sciences, grant number XDB20000000. The APC was funded by XDB20000000.

Conflicts of Interest: There are no conflicts to declare.

\section{References}

1. Zhang, S.; Rehrig, P.W.; Randall, C.; Shrout, T.R. Crystal growth and electrical properties of $\mathrm{Pb}\left(\mathrm{Yb}_{1 / 2} \mathrm{Nb}_{1 / 2}\right) \mathrm{O}_{3}-\mathrm{PbTiO}_{3}$ perovskite single crystals. J. Cryst. Growth 2002, 234, 415-420. [CrossRef]

2. Zhang, S.; Lebrun, L.; Jeong, D.Y.; Randall, C.A.; Zhang, Q.; Shrout, T.R. Growth and characterization of Fe-doped $\mathrm{Pb}\left(\mathrm{Zn}_{1 / 3} \mathrm{Nb}_{2 / 3}\right) \mathrm{O}_{3}-\mathrm{PbTiO}_{3}$ single crystals. J. Appl. Phys. 2003, 93, 9257-9262. [CrossRef]

3. Li, F.; Zhang, S.; Lin, D.; Luo, J.; Xu, Z.; Wei, X.; Shrout, T.R. Electromechanical properties of $\mathrm{Pb}\left(\mathrm{In}_{1 / 2} \mathrm{Nb}_{1 / 2}\right) \mathrm{O}_{3}-\mathrm{Pb}\left(\mathrm{Mg}_{1 / 3} \mathrm{Nb}_{2 / 3}\right) \mathrm{O}_{3}-\mathrm{PbTiO}_{3}$ single crystals. J. Appl. Phys. 2011, 109, 014108. [CrossRef] [PubMed]

4. Zhang, S.; Li, F. High performance ferroelectric relaxor- $\mathrm{PbTiO}_{3}$ single crystals: Status and perspective. J. Appl. Phys. 2012, 111, 2. [CrossRef]

5. Song, K.; Li, Z.; Guo, H.; Xu, Z.; Fan, S. Compositional segregation and electrical properties characterization of [001]- and [011]-oriented co-growth $\mathrm{Pb}\left(\mathrm{In}_{1 / 2} \mathrm{Nb}_{1 / 2}\right) \mathrm{O}_{3}-\mathrm{Pb}\left(\mathrm{Mg}_{1 / 3} \mathrm{Nb}_{2 / 3}\right) \mathrm{O}_{3}-\mathrm{PbTiO}_{3}$ single crystal. J. Appl. Phys. 2018, 123, 154107. [CrossRef]

6. Schader, F.H.; Rossetti, G.A., Jr.; Luo, J.; Webber, K.G. Piezoelectric and ferroelectric properties of $<001>_{\mathrm{C}} \mathrm{Pb}\left(\mathrm{In}_{1 / 2} \mathrm{Nb}_{1 / 2}\right) \mathrm{O}_{3}-\mathrm{Pb}\left(\mathrm{Mg}_{1 / 3} \mathrm{Nb}_{2 / 3}\right) \mathrm{O}_{3}-\mathrm{PbTiO}_{3}$ single crystals under combined thermal and mechanical loading. Acta Mater. 2017, 126, 174-181. [CrossRef]

7. Wang, Z.; He, C.; Li, X.; Liu, Y.; Long, X.; Han, S.; Pan, S. Scandium modified lead magnesium niobate-lead titanate single crystals for high temperature and high power applications. Mater. Lett. 2016, 184, 162-165.

8. Li, X.; Wang, Z.; Liu, Y.; He, C.; Long, X. A new ternary ferroelectric crystal of $\mathrm{Pb}\left(\mathrm{Y}_{1 / 2} \mathrm{Nb}_{1 / 2}\right) \mathrm{O}_{3}-\mathrm{Pb}\left(\mathrm{Mg}_{1 / 3} \mathrm{Nb}_{2 / 3}\right) \mathrm{O}_{3}-\mathrm{PbTiO}_{3}$. CrystEngComm 2014, 16, 7552-7557. [CrossRef]

9. Shirane, G.; Pepinsky, R. X-ray and neutron diffraction study of ferroelectric $\mathrm{PbTiO}_{3}$. Acta Cryst. 1956, 9, 131-140. [CrossRef]

10. Liu, Q.J.; Zhang, N.C.; Liu, F.S.; Wang, H.Y.; Liu, Z.T. $\mathrm{BaTiO}_{3}$ : Energy, geometrical and electronic structure, relationship between optical constant and density from first-priciples calculations. Opt. Mater. 2013, 35, 2629-2637. [CrossRef]

11. Goldschmidt, V.M. Die Gesetze der Krystallochemie. Naturwissenschaften 1926, 14, 477-485. [CrossRef]

12. Rödel, J.; Jo, W.; Seifert, K.T.P.; Anton, E.M.; Granzow, T.; Damjanovic, D. Perspective on the development of lead-free piezoceramics. J. Am. Ceram. Soc. 2009, 92, 1153-1177. [CrossRef]

13. Suchomel, M.R.; Davies, P.K. Predicting the position of the morphotropic phase boundary in high temperature $\mathrm{PbTiO}_{3}-\mathrm{Bi}\left(\mathrm{B}^{\prime} \mathrm{B}^{\prime \prime}\right) \mathrm{O}_{3}$ based dielectric ceramics. J. Appl. Phys. 2004, 96, 4405-4410. [CrossRef]

14. Park, S.-E.; Shrout, T.R. Ultrahigh strain and piezoelectric behavior in relaxor based ferroelectric single crystals. J. Appl. Phys. 1997, 82, 1804-1811. [CrossRef]

15. Li, X.; Wang, Z.; He, C.; Liu, Y.; Long, X.; Han, S.; Pan, S. High piezoelectric response of a new ternary ferroelectric $\mathrm{Pb}\left(\mathrm{Ho}_{1 / 2} \mathrm{Nb}_{1 / 2}\right) \mathrm{O}_{3}-\mathrm{Pb}\left(\mathrm{Mg}_{1 / 3} \mathrm{Nb}_{2 / 3}\right) \mathrm{O}_{3}-\mathrm{PbTiO}_{3}$ single crystal. Mater. Lett. 2015, 143, 88-90. [CrossRef]

16. He, C.; Li, X.; Wang, Z.; Liu, Y.; Shen, D.; Li, T.; Long, X. Compositional dependence of properties of $\mathrm{Pb}\left(\mathrm{Yb}_{1 / 2} \mathrm{Nb}_{1 / 2}\right) \mathrm{O}_{3}-\mathrm{Pb}\left(\mathrm{Mg}_{1 / 3} \mathrm{Nb}_{2 / 3}\right) \mathrm{O}_{3}-\mathrm{PbTiO}_{3}$ ternary ferroelectric crystals. CrystEngComm 2012, 14, 4513-4519. [CrossRef]

17. Liu, Y.; He, C.; Yang, X.; Li, X.; Wang, Z.; Huang, Z.; Lai, F.; Long, X. Growth and characterization of $\mathrm{Pb}\left(\mathrm{Lu}_{1 / 2} \mathrm{Nb}_{1 / 2}\right) \mathrm{O}_{3}-\mathrm{Pb}\left(\mathrm{Mg}_{1 / 3} \mathrm{Nb}_{2 / 3}\right) \mathrm{O}_{3}-\mathrm{PbTiO}_{3}$ ternary piezo-/ferroelectric crystals. J. Alloy. Compd. 2016, 675, 8-14. [CrossRef]

18. Liang, Z.; Sun, E.; Liu, Z.; Zhang, Z.; Zeng, J.; Ruan, W.; Li, G.; Cao, W. Electric field induced upconversion fluorescence enhancement and its mechanism in $\mathrm{Er}^{3+}$ doped $0.75 \mathrm{~Pb}\left(\mathrm{Mg}_{1 / 3} \mathrm{Nb}_{2 / 3}\right) \mathrm{O}_{3}-0.25 \mathrm{PbTiO}_{3}$ transparent ceramic. Appl. Phys. Lett. 2016, 109, 132904. [CrossRef] 
19. Li, F.; Lin, D.; Chen, Z.; Cheng, Z.; Wang, J.; Li, C.; Xu, Z.; Huang, Q.; Liao, X.; Chen, L.Q.; et al. Ultrahigh piezoelectricity in ferroelectric ceramics by design. Nat. Mater. 2018, 17, 349-354. [CrossRef]

20. Ji, W.; He, X.; Cheng, W.; Qiu, P.; Zeng, X.; Xia, B.; Wang, D. Effect of La content on dielectric, ferroelectric and electro-optic properties of $\mathrm{Pb}\left(\mathrm{Mg}_{1 / 3} \mathrm{Nb}_{2 / 3}\right) \mathrm{O}_{3}-\mathrm{PbTiO}_{3}$ transparent ceramics. Ceram. Int. 2015, 41, 1950-1956. [CrossRef]

21. Larson, A.C.; Von Dreele, R.B. General Structure Analysis System (GSAS), Los Alamos National Laboratory Report LAUR 86-748; Los Almos National Laboratory: Los Almos, NM, USA, 2004.

22. Shannon, R.D. Revised effective ionic radii and systematic studies of interatomic distances in halides and chalcogenides. Acta Cryst. 1976, A32, 751-767. [CrossRef]

23. Sayouri, S.; Kellati, M.; Taibi, M.; Moudden, N.E.; Tlemçani, M.; Ghazouali, A.E.; Kaal, A. Diffuse phase transition and relaxor behavior in (Pb,La) $\mathrm{TiO}_{3}$ ceramics. Phys. Stat. Sol. A 2004, 201, 3001-3009. [CrossRef]

24. Kim, T.Y.; Jang, H.M.; Cho, S.M. Effects of La doping on the cubic-tetragonal phase transition and short-range ordering in $\mathrm{PbTiO}_{3}$. J. Appl. Phys. 2002, 91, 336-343. [CrossRef]

25. Kalyani, A.K.; Garg, R.; Ranjan, R. Tendency to promote ferroelectric distortion in Pr-modified $\mathrm{PbTiO}_{3}$. Appl. Phys. Lett. 2009, 95, 222904. [CrossRef]

26. Bouwma, J.; Heilbron, M.A. Non-stoichiometry and optical spectra of $\mathrm{Nd}(\mathrm{III})$ substituted $\mathrm{PbTiO}_{3}$. Mater. Res. Bull. 1976, 11, 663-668. [CrossRef]

27. Xue, W.R.; Schulze, W.A.; Newnham, R.E. Effects of $\mathrm{Sm}_{2} \mathrm{O}_{3}$ and $\mathrm{Gd}_{2} \mathrm{O}_{3}+\mathrm{Nd}_{2} \mathrm{O}_{3}$ on electromechanical properties of PbTiO3 ceramics. J. Am. Ceram. Soc. 1990, 73, 1783-1784. [CrossRef]

28. Kchikech, M.; Maglione, M. Electronic and lattice excitations in $\mathrm{BaTiO}_{3}$ : La. J. Phys. Condens. Matter 1994, 6, 10159-10170. [CrossRef]

29. Yao, Z.; Liu, H.; Liu, Y.; Wu, Z.; Shen, Z.; Liu, Y.; Cao, M. Structure and dielectric behavior of Nd-doped $\mathrm{BaTiO}_{3}$ perovskites. Mater. Chem. Phys. 2008, 109, 475-481. [CrossRef]

30. Park, I.J.; Han, Y.H. Effects of synthesized method on the properties of Sm-doped $\mathrm{BaTiO}_{3}$. Met. Mater. Int. 2014, 20, 1157-1161. [CrossRef]

31. Ganguly, M.; Rout, S.K.; Woo, W.S.; Ahn, C.W.; Kim, I.W. Characterization of A-site deficient samarium doped barium titanate. Physica B 2013, 411, 26-34. [CrossRef]

32. Petrović, M.M.V.; Grigalaitis, R.; Ilic, N.; Bobić, J.D.; Dzunuzovic, A.; Banys, J.; Stojanović, B.D. Interdependence between structure and electrical characteristics in Sm-doped barium titanate. J. Alloy. Compd. 2017, 724, 959-968. [CrossRef]

33. Hwang, J.H.; Han, Y.H. Electrical properties of cerium-doped $\mathrm{BaTiO}_{3}$. J. Am. Ceram. Soc. 2001, 84, 1750-1754. [CrossRef]

34. Xie, S.; Bai, Y.; Han, F.; Qin, S.; Li, J.; Qiao, L.; Guo, D. Distinct effects of Ce doping in A or B sites on the electrocaloric effect of $\mathrm{BaTiO}_{3}$ ceramics. J. Alloy. Compd. 2017, 724, 163-168. [CrossRef]

35. Zhang, Y.; Sun, X.; Lu, D. Effects of cerium doping at Ti sites and europium doping at Ba sites on dielectric properties of $\mathrm{BaTiO}_{3}$ ceramics. Chem. Res. Chinese Univ. 2006, 22, 515-519. [CrossRef]

36. Lu, D.Y.; Koda, T.; Suzuki, H.; Toda, M. Structure and dielectric properties of Eu-doped barium titanate ceramics. J. Ceram. Soc. Jpn. 2005, 113, 721-727. [CrossRef]

37. Sitko, D.; Garbarz-Glos, B.; Piekarczyk, W.; Śmiga, W.; Antonova, M. The effects of the additive of Eu ions on elastic and electric properties of $\mathrm{BaTiO}_{3}$ ceramics. Integr. Ferroelectr. 2016, 173, 31-37. [CrossRef]

38. Mizuno, Y.; Kishi, H.; Ohnuma, K.; Ishikawa, T.; Ohsato, H. Effect of site occupancies of rare earth ions on electrical properties in Ni-MLCC based on $\mathrm{BaTiO}_{3}$. J. Eur. Ceram. Soc. 2007, 27, 4017-4020. [CrossRef]

39. Ben, L.; Sinclair, D.C. Anomalous Curie temperature behavior of A-site Gd-doped $\mathrm{BaTiO}_{3}$ ceramics: The influence of strain. Appl. Phys. Lett. 2011, 98, 092907. [CrossRef]

40. Buscaglia, M.T.; Buscaglia, V.; Viviani, M.; Nanni, P.; Hanuskova, M. Influence of foreign ions on the crystal structure of $\mathrm{BaTiO}_{3}$. J. Eur. Ceram. Soc. 2000, 20, 1997-2007. [CrossRef]

41. Lee, E.J.; Jeong, J.; Han, Y.H. Electrical Properties of $\mathrm{Dy}_{2} \mathrm{O}_{3}$-doped $\mathrm{BaTiO}_{3}$. Jpn. J. Appl. Phys. 2004, 43, 8126-8129. [CrossRef]

42. Lu, D.Y.; Cui, S.Z. Defects characterization of Dy-doped $\mathrm{BaTiO}_{3}$ ceramics via electron paramagnetic resonance. J. Eur. Ceram. Soc. 2014, 34, 2217-2227. [CrossRef]

43. Paunović, V.; Mitić, V.V.; Miljković, M.; Pavlović, V.; Živković, L. $\mathrm{Ho}_{2} \mathrm{O}_{3}$ additive effects on $\mathrm{BaTiO}_{3}$ ceramics microstructure and dielectric properties. Sci. Sinter. 2012, 44, 223-233. [CrossRef] 
44. Jeong, J.; Lee, E.J.; Han, Y.H. Effects of $\mathrm{Ho}_{2} \mathrm{O}_{3}$ addition on defects of $\mathrm{BaTiO}_{3}$. Mater. Chem. Phys. 2006, 100, 434-437. [CrossRef]

45. Lu, D.Y.; Gao, X.L.; Wang, S. Abnormal Curie-temperature shift in Ho-doped $\mathrm{BaTiO}_{3}$ ceramics with the self-compensation mode. Results Phys. 2019, 12, 585-591. [CrossRef]

46. Hwang, J.H.; Han, Y.H. Dielectric properties of erbium doped barium titanate. Jpn. J. Appl. Phys. 2001, 40, 676-679. [CrossRef]

47. Song, Y.H.; Han, Y.H. Effects of rare-earth oxides on temperature stability of acceptor-doped BaTiO 3 . Jpn. J. Appl. Phys. 2005, 44, 6143-6147. [CrossRef]

48. Ganguly, M.; Rout, S.K.; Ahn, C.W.; Kim, I.W.; Kar, M. Structural, electrical and optical properties of $\mathrm{Ba}\left(\mathrm{Ti}_{1-x} \mathrm{Yb}_{4 x / 3}\right) \mathrm{O}_{3}$ ceramics. Ceram. Int. 2013, 39, 9511-9524. [CrossRef]

49. Hahn, D.W.; Han, Y.H. Electrical Properties of Yb-Doped $\mathrm{BaTiO}_{3}$. Jpn. J. Appl. Phys. 2009, 48, 111406. [CrossRef]

50. Molokhia, N.M.; Issa, M.A.A.; Nasser, S.A. Dielectric and X-Ray diffraction studies of barium titanate doped with ytterbium. J. Am. Ceram. Soc. 1984, 67, 289-291. [CrossRef]

51. Yakovlev, S.; Solterbeck, C.H.; Skou, E.; Es-Souni, M. Structural and dielectric properties of Er substituted sol-gel fabricated $\mathrm{PbTiO}_{3}$ thin films. Appl. Phys. A 2006, 82, 727-731. [CrossRef]

52. Peláiz-Barranco, A.; Méndez-González, Y.; Arnold, D.C.; Saint-Grégoire, P.; Keeble, D.J. Incorporation of lanthanide ions in lead titanate. J. Mater. Sci. 2012, 47, 1094-1099. [CrossRef]

53. Ganguly, M.; Rout, S.K.; Sinha, T.P.; Sharma, S.K.; Park, H.Y.; Ahn, C.W.; Kim, I.W. Characterization and Rietveld refinement of A-site deficient lanthanum doped barium titanate. J. Alloy. Compd. 2013, 579, 473-484. [CrossRef]

54. Cohen, R.E. Origin of ferroelectricity in perovskite oxides. Nature 1992, 358, 136-138. [CrossRef]

55. Culberson, J.C.; Knappe, P.; Rösch, N.; Zerner, M.C. An intermediate neglect of differential overlao (INDO) technique for lanthanide complexes: Studies on lanthanide halides. Theor. Chim. Acta 1987, 71, 21-39. [CrossRef]

56. Lide, D.R. CRC Handbook of Chemistry and Physics; CRC Press: Boca Raton, FL, USA, 2002; pp. 9-51.

57. Warren, W.L.; Dimos, D.; Tuttle, B.A.; Pike, G.E.; Schwartz, R.W.; Clews, P.J.; Mclntyre, D.C. Polarization suppression in $\mathrm{Pb}(\mathrm{Zr}, \mathrm{Ti}) \mathrm{O}_{3}$ thin films. J. Appl. Phys. 1995, 77, 6695-6702. [CrossRef]

58. Tagantsev, A.K.; Stolichnov, I.; Colla, E.L.; Setter, N. Polarization fatigue in ferroelectric films: Basic experimental findings, phenomenological scenarios, and microscopic features. J. Appl. Phys. 2001, 90, 1387-1402. [CrossRef]

59. Schenk, T.; Yurchuk, E.; Mueller, S.; Schroeder, U.; Starschich, S.; Böttger, U.; Mikolajick, T. About the deformation of ferroelectric hysteresis. Appl. Phys. Rev. 2014, 1, 041103. [CrossRef]

60. Slodczyk, A.; Daniel, P.; Kania, A. Local phenomena of $(1-x) \mathrm{PbMg}_{1 / 3} \mathrm{Nb}_{2 / 3} \mathrm{O}_{3}-x \mathrm{PbTiO}_{3}$ single crystals $(0 \leq x \leq 0.38)$ studied by Raman scattering. Phys. Rev. B 2008, 77, 184114. [CrossRef]

61. Welsch, A.M.; Maier, B.J.; Mihailova, B.; Angel, R.J.; Zhao, J.; Paulmann, C.; Engel, J.M.; Gospodinov, M.; Marinova, V.; Bismayer, U. Transformation processes in relaxor ferroelectric $\mathrm{PbSc}_{0.5} \mathrm{Ta}_{0.5} \mathrm{O}_{3}$ heavily doped with $\mathrm{Nb}$ and Sn. Z. Krist. Cryst. Mater. 2011, 226, 126-137. [CrossRef]

62. Deluca, M.; Fukumura, H.; Tonari, N.; Capiani, C.; Hasuike, N.; Kisoda, K.; Galassi, C.; Harima, H. Raman spectroscopic study of phase transitions in undoped morphotropic $\mathrm{PbZr}_{1-x} \mathrm{TiO}_{3}$. J. Raman Spectrosc. 2011, 42, 488-495. [CrossRef]

63. Husson, E.; Abello, L.; Morell, A. Short-range order in $\mathrm{PbMg}_{1 / 3} \mathrm{Nb}_{2 / 3} \mathrm{O}_{3}$ ceramics by Raman spectroscopy. Mater. Res. Bull. 1990, 25, 539-545. [CrossRef]

64. Igarashi, K.; Koumoto, K.; Yanagida, H. Ferroelectric Curie points at perovskite-type oxides. J. Mater. Sci. 1987, 22, 2828-2832. [CrossRef]

65. Sinclair, D.C.; Attfiled, J.P. The influence of A-cation disorder on the Curie temperature of ferroelectric $\mathrm{ATiO}_{3}$ perovskites. Chem. Commun. 1999, 16, 1497-1498. [CrossRef]

66. Attfield, J.P. Structure-property relations in doped perovskite oxides. Inter. J. Inorg. Mater. 2001, 3, 1147-1152. [CrossRef]

(C) 2020 by the authors. Licensee MDPI, Basel, Switzerland. This article is an open access article distributed under the terms and conditions of the Creative Commons Attribution (CC BY) license (http://creativecommons.org/licenses/by/4.0/). 